\title{
Effects of Nicotine Nasal Spray on Cognitive Function in Schizophrenia
}

\author{
Robert C Smith*, 1,2, Jessy Warner-Cohen ${ }^{3}$, Melissa Matute ${ }^{2,4}$, Erin Butler ${ }^{2}$, Erin Kelly ${ }^{2}$, \\ Sumathi Vaidhyanathaswamy ${ }^{2,6}$ and Alea Khan ${ }^{5}$ \\ 'Department of Psychiatry, New York University Medical School, Hewlett, NY, USA; ${ }^{2}$ Manhattan Psychiatric Center, Wards Island, NY, USA; \\ ${ }^{3}$ Department of Psychology, University of Maryland, Baltimore County, Baltimore, MD, USA; ${ }^{4}$ Queens College, Queens, NY, USA; ${ }^{5}$ Bryn Mawr \\ College, Bryn Mawr, PA, USA
}

\begin{abstract}
Schizophrenics have among the highest rates of cigarette smoking. Some studies indicate that cigarette smoking or nicotine may ameliorate some of the cognitive or theoretically related neurophysiological deficits seen in schizophrenic patients. This study investigated the effects of nicotine nasal spray on measures of attention, verbal memory, and visual-spatial memory in schizophrenic patients who were chronic smokers, using a double-blind placebo-controlled pre-post experimental design. Compared to placebo, active nicotine spray significantly decreased reaction time on the Conner's CPT and improved scores on a measure purported to reflect spatial working memory on a dot task. There were trends for the increased number of hits and decreased number of errors in pre-post comparisons on the CPT task in the active nicotine session. There were no effects of active nicotine nasal spray on verbal memory. Our results suggest that nicotine may modestly enhance attention and spatial working memory in schizophrenic patients who are cigarette smokers and have been abstinent overnight.

Neuropsychopharmacology (2006) 3 I, 637-643. doi: I 0.1038/sj.npp. I 30088I; published online I4 September 2005
\end{abstract}

Keywords: nicotine; schizophrenia; smoking; attention; visual-spatial memory; verbal memory

\section{INTRODUCTION}

Schizophrenics have a higher rate of cigarette smoking than patients with other psychiatric diagnoses or patients without definite psychiatric diagnoses (Dalack et al, 1998; Glassman, 1993). In some studies, rates of smoking among schizophrenic patients have ranged from 80 to $90 \%$ (Dalack et al, 1998). It has been hypothesized that smoking may compensate for physiological deficits in schizophrenia deriving from decreases in number or structure, or differences in physiological response, of nicotinic receptors, which may lead to affective and cognitive deficits in schizophrenic patients, and this may be involved as an explanation for the high rate of smoking in schizophrenics (Glassman, 1993). Recent studies have presented evidence that nicotine administration or cigarette smoking transiently corrects or ameliorates some of the psychophysio-

\footnotetext{
*Correspondence: Dr RC Smith, NYU Medical School, Department of Psychiatry, c/o PO Box 316, Hewlett, NY, USA, Tel: + I 6466726910 , 516569 |810, Fax: + | 516569 1755,

E-mail: robert.smith@med.nyu.edu

${ }^{6}$ Now at Department of Psychiatry, Lincoln Hospital, Bronx, NY, USA Received 17 February 2005; revised 13 June 2005; accepted 20 July 2005

Online publication: I August 2005 at http://www.acnp.org/citations/ Npp072605050 105/default.pdf
}

logical abnormalities found in schizophrenic patients. Specifically, in schizophrenics, smoking a cigarette corrected the diminished gating response of the P50 auditory evoked potential in a two-tone prepulse habituation paradigm, and also reduced abnormalities in smooth pursuit eye movements reported to occur in schizophrenia (Adler et al, 1993; Adler et al, 1992; Olincy et al, 1998). Although these physiological parameters are theoretically related to the cognitive process, the neuropsychological effects cannot be directly extrapolated from the physiological effects of nicotine in schizophrenic patients, and warrant direct investigation.

Our own prior study (Smith et al, 2002), and several other recent studies (George et al, 2002; Depatie et al, 2002; Levin et al, 1996), reported positive effects of cigarette smoking or other forms of nicotine administration (patch, nasal spray) on neuropsychological test measures in schizophrenic patients. These studies showed improved performance scores on cognitive tests in schizophrenic patients after cigarette or nicotine administration in pre-post or separate sessions crossover placebo-controlled designs, or better cognitive performance in schizophrenics maintained on cigarettes compared to those who had stopped smoking. The cognitive test measures that showed improved performance included (a) attention and vigilance (on CPT test and two choice reaction time), (b) spatial organization test from ANAM battery, (c) measurers of visual-spatial memory 
derived from a dot task, and (d) verbal memory measured by sections of the RANDT memory scale.

Nicotine nasal spray has a pharmacokinetic profile, which is more similar to cigarette smoking than other forms of nicotine administration (patch or gum). In our prior study (Smith et al, 2002), nicotine nasal spray had effects on some of the cognitive measures, but these cognitive effects were assayed later in the session after the second or third administration of nicotine nasal spray, which was administered three times, 30-45 min apart, over a $1.5-2 \mathrm{~h}$ period. This schedule of repeated administration may have compromised the interpretation or strength of some of the cognitive effects because rapid tolerance develops to some of nicotine's effects, which may be related to rapid desensitization of nicotinic receptors. Previous research has suggested that the most rapid desensitization rate may be found in the a-7 nicotinic receptors, which are prevalent in the hippocampus (Domino, 1998; Stevens et al, 1998), and which have been hypothesized to be important in nicotine's effects on psychophysiological and cognitive function in schizophrenic patients. Therefore, in the current experiment we tested cognitive effects of nicotine in the first 15$30 \mathrm{~min}$ after a single high-dose administration of nicotine nasal spray.

On the basis of prior results of our own study and reports of other researchers as noted above, we predicted that nicotine nasal would improve measures of attention or vigilance on the $\mathrm{CPT}$, improve performance on spatial organization and spatial working memory, and improve short-term verbal memory. We also predicted that active nicotine nasal spray would slightly increase pulse and blood pressure.

\section{METHOD}

\section{Subjects}

Subjects were 27 male patients with DSM-IV diagnosis of schizophrenia or schizoaffective disorder who were hospitalized in a tertiary care hospital and were chronic cigarette smokers, who had smoked at least six cigarettes/day when they were in an environment which did not restrict smoking. Characteristics of the patients, their current antipsychotic treatment, and smoking history are shown in Table 1. Subjects could be treated with accessory psychiatric medications (primarily mood stabilizers) and medications for any medical conditions (primarily hypertension and hypercholesterolemia). Psychotropic medication was not changed during the 2-4 week course of the study. Subjects signed informed consent in a protocol approved by the Manhattan Psychiatric Center and Nathan Kline Institute's IRBs.

\section{Design}

The study had a double-blind placebo-controlled design where subjects received active or placebo nicotine nasal spray. The experimental design consisted of five separate sessions, one nasal spray habituation session, and four experimental sessions. In the nasal spray habituation session, the subjects received up to four nasal spray administrations separated by $10-15 \mathrm{~min}$ and also completed
Table I Patient Characteristics

\begin{tabular}{lc}
\hline Variable & N or Mean \pm SD \\
\hline Age $(M)$ & $37.59 \pm 8.27$ \\
Sex $(M / F)(N)$ & $26 / 0$ \\
Cigarettes smoked/day (M, [Range]) & $10.96 \pm 4.79[6-24]$ \\
Years smoke (M) & $17.15 \pm 8.62$ \\
DSM-IV diagnoses (schizophrenia/schizoaffective disorder) & $19 / 8$ \\
& \\
Antipsychotic drug (N) & \\
Clozapine & 13 \\
Olanzapine & 10 \\
Risperidone & 1 \\
Conventional & 1 \\
More than one antipsychotic & 1 \\
\hline
\end{tabular}

$M=$ mean, $N=$ number; cigarettes smoked per day in hospital when they had free access to smoking periods.

the computerized neurocognitive tests to give the subjects familiarity with these tests. The design of the 4 experimental day sessions is outlined in Table 2. In two of the experimental sessions, the patient received active nicotine nasal spray and in two sessions matched placebo nasal spray, both provided by Pharmacia UpJohn. The order of either having the two active nicotine spray sessions first or the two placebos spray sessions first was randomized.

In each session, the patient had abstained from smoking for $10-12 \mathrm{~h}$ (since late the prior evening) before he came to the experimental session the next morning. Lack of smoking was certified both by verbal questioning and breathalyzer (BreathCO carbon monoxide monitor) carbon monoxide test reading of $\mathrm{CO}<10 \mathrm{ppm}$. Patients who reported smoking in the last $10-12 \mathrm{~h}$ or had CO levels $>10$ were not run in their scheduled experimental session. Subjects had their blood pressure and pulse checked twice with an Omron automatic blood pressure meter, and mean values of blood pressure and pulse were entered for analyses. Subjects then completed pre-drug tests on one of two batteries of neuropsychological tests. In the first and third experimental sessions they were tested on Conner's CPT (Psychological Corporation, 1988) (shorted to $7 \mathrm{~min}$ length) and were then administered the spatial rotation test from the ANAM (Reeves et al, 1993) (4-5 min). After a $5 \mathrm{~min}$ break, they were tested on the paper and pencil visual-spatial dot memory test (Keefe et al, 1995) for immediate memory, and delayed memory after interfering task, with modifications described previously (Smith et al, 2001) (10-12 min). In the second and fourth experimental sessions, they were tested for verbal memory using the verbal portion of the RANDT memory scale (Randt and Brown, 1983) before and after drug administration (four equivalent alternate forms). After completing the pre-drug testing in each session, they were given active or placebo nasal spray, four puffs to each nostril, and retested for blood pressure and pulse 3-5 $\mathrm{min}$ later. They were then retested on the same neurocognitive battery they had been tested on in the pre-drug testing of that same day. After completing the testing, a blood sample was drawn for the measurement of plasma nicotine and cotinine. 


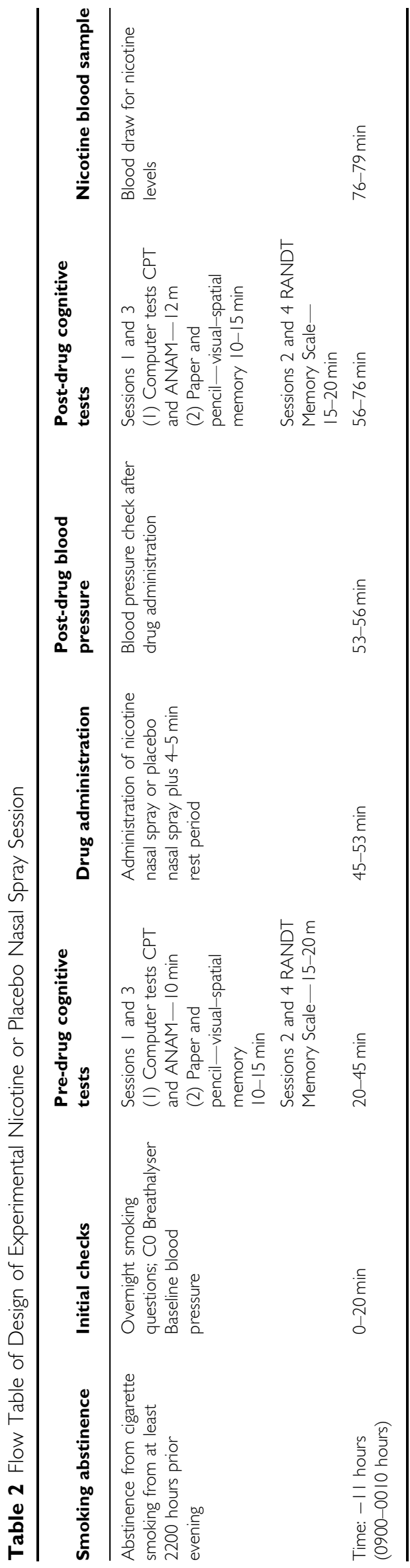

The cognitive tests were broken up into two separate sessions to allow most tests to be completed close to the peak nicotine levels after a nasal spray administration. This design may have also served to reduce the desensitization of nicotinic receptors, which might be more likely to occur with repeated nicotine administration over $30-90 \mathrm{~min}$, as may have been the case in our earlier experiment (Smith et al, 2002). After a single nasal spray administration, peak nicotine levels usually occur in $8-15 \mathrm{~min}$, with first-phase half-life drop off over the next $60 \mathrm{~min}$ (Pharmacia, 1993; Russel et al, 1983). Furthermore, some of our seriously ill hospitalized patients with schizophrenia could not sustain attention and cooperation in cognitive testing for longer periods of time, and, therefore, the shorter sessions may have aided obtaining more accurate data on their effortful cognitive performance.

\section{Nicotine and Cotinine Assay}

Nicotine and cotinine were assayed in plasma in the Analytical Chemistry Laboratory at the Nathan Kline Institute for Psychiatric Research. The assay is a GC/MS assay, following the procedure described in Davis (1986) with modifications for GC/MS detection. The method involves liquid/liquid extraction with $\mathrm{N}$-ethyl nornicotine and Nicotine D4 and Cotinine D3 as internal standards. Separation is achieved via gas chromatography with a Restek RtX-5 amine $15 \mathrm{~m} 0.25 \mathrm{ID} 0.50 \mu \mathrm{m}$ df, crossbond 5\% diphenyl 95\% dimethylpolysilixane column. Nicotine is run in PCI mode, target ion 163, and cotinine is run in EI mode, target ion 98. The detection limit of accurate quantification of nicotine with this assay is $3 \mathrm{ng} / \mathrm{ml}$ with intra- and intercoefficients of variation of 4.7 and $5.9 \%$. Cotinine limit of detection is $5 \mathrm{ng} / \mathrm{ml}$ with intra- and interassay coefficient of variation of 3.4 and $5.2 \%$ respectively. Since the sensitivity of the assay was $3 \mathrm{ng} / \mathrm{ml}$, assay results which were reported as $<3 \mathrm{ng} / \mathrm{ml}$ were coded as $2 \mathrm{ng} / \mathrm{ml}$ and assay results which were reported as 'nondetectable' were coded as 0 .

\section{Statistical Analysis}

Statistical analysis used SPSS 12.0 general linear model repeated measures analysis of variance with drug order as a between-subjects factor. If Mauchy's test for sphericity was significant, results based on Greenhouse-Geiser corrections were used for within subjects ANOVA. Paired $t$-tests were used to compare the significance of pre- $v s$ post difference of a specific score on a single test day. For those tests for which we had prior directional predictions based on previous research (see Introduction above), one-tailed significance was utilized, and two-tailed significance levels were utilized where we had not specified a directional prediction.

We examined the effects of differences in plasma nicotine levels on cognitive effects by performing correlations of nicotine levels with changes in pre- $v s$ post-cognitive scores in the active nicotine nasal spray session, and comparing improvements in performance of those subjects with nicotine levels above and below two dividing points.

The hospital instituted a no-smoking policy for hospitalized patients before the study sample was completed. Six of 
our schizophrenic subjects who were chronic cigarette smokers did not have free access to cigarettes for several months before they participated in the study. Although violation of the no-smoking policy by illicit cigarette smoking was fairly frequent among patients in the hospital, we do not have accurate data on the extent of illicit smoking by these six specific patients. To examine whether the factor of free access to cigarettes could have influenced our results, we performed subsidiary ANOVA's including time of subjects participation in the experiment-pre-smoking ban $v s$ post-smoking ban - as an additional fixed factor. We also performed separate paired $t$-tests in the active nicotine sessions, for the subjects who were run before and after the smoking ban, on the variables that showed significant or near significant effects in the original analysis.

Effects sizes were measured by partial Eta square for the complete ANOVA's (SPSS), and also by Cohen's $d$ (Cohen, 1988) for comparison of pre- $v s$ post-drug effects in the active drug session.

\section{RESULTS}

\section{Physiological}

Carbon monoxide levels at a pre-drug administration baseline in all sessions were $<10 \mathrm{ppm}$ in all subjects (range
$0-8)$, and mean carbon monoxide levels ranged from 1.9 to 2.5. In the active nicotine nasal spray sessions, plasma nicotine levels drawn about $30 \mathrm{~min}$ after nasal spray administration had a mean ( \pm s.d.) of $9.4 \pm 6.9 \mathrm{ng} / \mathrm{ml}$ in experimental session 1 and $8.3 \pm 7.0 \mathrm{ng} / \mathrm{ml}$ in session 2 (range $0-30 \mathrm{ng} / \mathrm{ml}$ ); cotinine levels means were $252 \pm 142$ and $235 \pm 127 \mathrm{ng} / \mathrm{ml}$ in the same two sessions (range 12502). In a subsample of 10 patients for whom we were able to analyze nicotine levels after placebo spray session, mean nicotine levels were $2.6 \pm 4.9 \mathrm{ng} / \mathrm{ml}$ (range $0-13$ ) and mean cotinine levels $187 \pm 105 \mathrm{ng} / \mathrm{ml}$ (range 77-383). Plasma cotinine levels in these placebo sessions were slightly higher $(p=0.10)$ in five of these 10 subjects who were enrolled before the institution of the smoking ban $(244 \pm 116 \mathrm{ng} / \mathrm{ml})$ than in the five subjects enrolled after the smoke ban $(130 \pm 76 \mathrm{ng} / \mathrm{ml})$, but four of five subjects in the smoke ban condition had substantial cotinine levels (>90 ng/ml). Although we did not draw samples to determine nicotine levels at baseline (pre-nasal spray) in this study, preliminary data from a subsequent ongoing study we are currently performing, with a similar group of patients in a slightly different cognitive test, showed mean pre-drug nicotine levels of $1.68 \mathrm{ng} / \mathrm{ml}$. Additionally, our earlier published study (Smith et al, 2002) showed mean pre-drug nicotine levels in the nasal spray sessions of $2.78-3.82 \mathrm{ng} / \mathrm{ml}$. Active nicotine nasal spray had a small but statistically significant

Table 3 Effects of Active and Placebo Nicotine Nasal Spray on Measures of Attention and Visual-Spatial Memory

\begin{tabular}{|c|c|c|c|c|c|c|}
\hline \multirow{3}{*}{$\begin{array}{l}\text { Measure } \\
\text { Blood pressure and pulse }(N=27)\end{array}$} & \multicolumn{2}{|c|}{ Active nicotine spray } & \multicolumn{2}{|c|}{ Placebo nicotine spray } & \multirow{2}{*}{\multicolumn{2}{|c|}{$\begin{array}{l}\text { Statistical analysis - overall } \\
\text { repeated measures ANOVA } \\
\text { nicotine effect (F, interaction } \\
\text { - Pre- vs post-drug) and effect size } \\
\text { (partial eta square (ES)) }\end{array}$}} \\
\hline & \multirow[t]{2}{*}{ Pre-drug } & \multirow[t]{2}{*}{ Post-drug } & \multirow[t]{2}{*}{ Pre-drug } & \multirow[t]{2}{*}{ Post-drug } & & \\
\hline & & & & & F, ANOVA & ES \\
\hline Pulse & $81.08 \pm 10.69^{a} * *$ & $86.76 \pm 12.73^{\mathrm{a} * * *}$ & $80.851 \pm 1.49^{b_{*} * * *}$ & $76.01 \pm 10.93^{b_{*} * *}$ & $F=12.444, d f=1,25, P=0.002$ & 0.33 \\
\hline Blood pressure systolic & $122.48 \pm 11.62^{\complement * * *}$ & $126.4 \pm 13.47^{c * * * *}$ & $121.01 \pm 12.50$ & $119.76 \pm 13.40$ & $F=6.186, d f=1,25, P=0.020$ & 0.20 \\
\hline Blood pressure diastolic & $76.37 \pm 8.14^{\mathrm{d} * * *}$ & $81.69 \pm 11.14^{\mathrm{d} * * *}$ & $76.44 \pm 8.18$ & $77.13 \pm 9.09$ & $\mathrm{~F}=6.688, \mathrm{df}=1,25, P=0.01$ & 0.21 \\
\hline \multicolumn{7}{|l|}{ Attention-vigilance $(\mathrm{N}=24-26)$} \\
\hline CPT number hits (correct) & $|52.7| \pm|0.6|^{\mathrm{e}}$ & $155.92 \pm 6.45^{\mathrm{e} \ddagger}$ & $154.67 \pm 8.82$ & $154.42 \pm 10.67$ & $F=2.294, d f=1,22, P=0.144$ & 0.09 \\
\hline CPT number omissions & $8.69 \pm 10.39^{f \ddagger}$ & $5.69 \pm 6.34^{\mathrm{f \ddagger}}$ & $6.88 \pm 8.60$ & $7.08 \pm 10.39$ & $\mathrm{~F}=2.128, \mathrm{df}=1,24, P=0.158$ & 0.08 \\
\hline CPT number commissions & $5.00 \pm 4.50$ & $5.81 \pm 4.62$ & $5.54 \pm 4.34$ & $5.19 \pm 3.54$ & $\mathrm{~F}=1.828, \mathrm{df}=1,24, P=0.189$ & 0.07 \\
\hline CPT hit reaction time (ms) & $491.44 \pm 117.03^{8}$ ***十 & $451.84 \pm 94.74^{g} * * * 6$ & $468.79 \pm 93.89$ & $466.26 \pm 99.90$ & $\mathrm{~F}=6.323, \mathrm{df}=1,24, P=0.019$ & 0.21 \\
\hline \multicolumn{7}{|l|}{ Visual-spatial memory (dot test) $(N=26)$} \\
\hline Immediate recall (error cm) & $1.23 \pm 0.80$ & $1.56 \pm 1.40$ & $1.38 \pm 1.12$ & $1.21 \pm 0.9 \mid$ & $\mathrm{F}=3.1 \mathrm{I} \mathrm{I}, \mathrm{df}=1,24, P=0.09$ & 0.12 \\
\hline Delayed recall (error cm) & $3.72 \pm 2.57$ & $3.34 \pm 1.93$ & $3.00 \pm 1.64$ & $3.12 \pm 1.55$ & $\mathrm{~F}=2.197, \mathrm{df}=1,24, P=0.296$ & 0.08 \\
\hline $\begin{array}{l}\text { Difference delayed minus immediate } \\
\text { (error } \mathrm{cm})\end{array}$ & $2.50 \pm 2.48^{h \dagger}$ & $1.78 \pm 1.81^{h \dagger}$ & $1.63 \pm 1.40$ & $1.92 \pm 1.43$ & $\mathrm{~F}=4.908, \mathrm{df}=1,24, P=0.036$ & 0.17 \\
\hline \multicolumn{7}{|l|}{ Spatial organization (ANAM) $(N=22)$} \\
\hline Percent accurate & $80.00 \pm 20.18^{1 *}$ & $87.5 \pm 12.98^{1} *$ & $83.72 \pm 14.68$ & $85.91 \pm 13.06$ & $F=1.488, d f=1,20, P=0.237$ & 0.07 \\
\hline Accuracy/time (throughput-correct/time) & $15.85 \pm 6.63^{j *}$ & $19.60 \pm 7.93^{j *}$ & $16.21 \pm 6.60$ & $17.06 \pm 5.43$ & $\mathrm{~F}=2.049, \mathrm{df}=1,20, P=0.168$ & 0.17 \\
\hline
\end{tabular}

Each number represents mean \pm SD. Means with similar superscripts are different, by paired $t$-test, directional-predicted one-tailed significance levels: ${ }^{\dagger} P<0.07$,

${ }^{\ddagger} P \leq 0.06, * P<0.03, * * P<0.01 . N=22$ for ANAM because the first five subjects did not perform this test. The overall ANOVA's (F) in the SPSS general linear model use two-tail significance. 
effect on pulse and blood pressure (Table 3), increasing pulse (about $4 \mathrm{bmp}$ ) and diastolic and systolic pressure (about $4-5 \mathrm{~mm} \mathrm{Hg}$ ). Placebo spray produced a decreased pulse of about the same extent.

\section{Cognitive Tests}

On the CPT task of attention vigilance, the only overall significant effect in the repeated measures ANOVA was the decrease in reaction time in the pre $v s$ post comparison of the active $v s$ placebo nasal spray sessions (ANOVA $P=0.019)$. However, paired $t$-tests in the active nasal spray sessions also showed a trend $(P<0.06)$ for an increase in the number of correct hits and decrease in the number of omissions (Table 3).

There were also some significant effects on spatial organization and visual memory tasks. Active nasal spray compared to placebo significantly (ANOVA $P=0.036$ ) decreased the difference in distance error of delayed $v s$ immediate recall in the dot task, and this measure has been interpreted as a measure of working spatial memory (Keefe et al, 1995) (Table 3). In the active nicotine session, there was a trend for a small nonsignificant $(P=0.11)$ decrease in errors in delayed memory and a stronger trend for a decrease in error of delayed $v s$ immediate memory $(P<0.07)$. In contrast, active nicotine nasal spray did not improve immediate recall on the dot task without an interfering task. In the active nicotine drug session, pre- vs post-drug comparisons showed an increase in accuracy $(P<0.03)$ on a spatial organization task from the ANAM battery, although the $\mathrm{F}$ from overall repeated measures ANOVA for drug $v s$ placebo was not significant.

There were no significant effects of nicotine nasal spray on verbal memory either immediately or after interference delay on the total score or subsection scores of the verbal memory sections of the RANDT Memory Scale in the overall ANOVA or subsequent within session tests. (The Total RANDT and some of the subscores were not predicted on the basis of previous data, and, therefore, some of these individual pre- $v s$ post-session differences were tested by two-tailed significance. However, they were also not significant by one-tailed tests.)

There were no significant correlations between plasma nicotine levels and changes in performance, pre- $v s$ postdrug administration, in the active nicotine session. There were also no significant differences in effect when subjects were divided into those who had nicotine levels $\leqslant 3 \mathrm{ng} / \mathrm{ml}$ compared to subjects who had nicotine levels $>3 \mathrm{ng} / \mathrm{ml}$, or comparing subjects with nicotine levels above and below $8 \mathrm{ng} / \mathrm{ml}$. In some comparisons for the CPT task, patients with higher nicotine levels had slightly higher mean improvement in performance scores, but none of the differences were statistically significant $(P$ 's $>0.05)$. Since there were a few patients who had appreciable nicotine levels in the placebo nasal spay session, additional ANOVA's analyses were performed, excluding patients who had nicotine levels $\geqslant 5 \mathrm{ng} / \mathrm{ml}$ in the placebo spray sessions; these ANOVA's did not improve the statistical significance $(\mathrm{F})$ of the drug effect.

The additional ANOVA's with pre- $v s$ post-smoking ban policy as a factor did not show a statistically significant interaction effect for smoke ban $\times$ nicotine nasal spray drug effect for any variable. Furthermore, when we performed ANOVA's on the subset of 21 more homogenous patients who were enrolled before the hospital smoking ban was instituted, these analyses did not show a consistently stronger statistical significance (F) than the full analysis reported above. However, as shown in Table 4, analysis of pre- $v s$ post-drug scores in the active nicotine nasal spray session, analyzed separately, generally showed a greater effect (improvement in scores) on CPT, ANAM, and dot task for subjects run before the smoking ban than for the six subjects run after the smoking ban; and for some of the measures there was a trend for difference in direction of effect.

Overall effect sizes were modest. In the full ANOVA model, effect size assessed by partial eta square ranged from 0.07 to 0.17 on the cognitive tests (Table 3 ). For the active

Table 4 Nicotine Effects of Cognitive Measures in Subjects Participating before or after Imposition of Hospital Smoking Ban

Mean difference in post-drug minus pre-drug test score in active nasal spray session

Test and measure

CPT
Number omissions
Number correct hits
Reaction time hits
ANAM
Spatial rotation (percent accurate)
Visual-spatial memory (dot test)
Delayed recall (cm error)
Delayed recall-immediate recall (cm error)
Blood pressure and pulse
Pulse (bpm)
Systolic blood pressure (mmHg)

Subjects run before hospital smoking ban

$$
\begin{gathered}
(N=20-21) \\
-3.91 \pm 9.14^{*} \\
4.05 \pm 9.35 * \\
-46.85 \pm 62.64 * * \\
(N=16) \\
9.11 \pm 18.98 * \\
(N=21) \\
-0.42 \pm 1.35^{\dagger} \\
-0.78 \pm 1.83^{*} \\
(N=21) \\
6.18 \pm 11.16 * * \\
3.96 \pm 7.08 * *
\end{gathered}
$$

Subjects run after hospital smoking ban

$$
\begin{gathered}
(N=5) \\
0.80 \pm 8.43 \\
-0.80 \pm 8.44 \\
-9.13 \pm 66.68 \\
(N=6) \\
1.67 \pm 8.76 \\
(N=6) \\
0.16 \pm 1.57 \\
0.12 \pm 2.41 \\
(N=6) \\
3.91 \pm 11.48 \\
4.12 \pm 5.65
\end{gathered}
$$

Each number represents Mean \pm SD of pre-post-drug administration difference score. Statistical significance (from ' 0 ' difference) by paired $t$-test, one-tailed significance: $* P<0.05,{ }^{*} * P<0.01,{ }^{\dagger} P<0.10$. 
nicotine session, Cohen's $d$ measure of effect size varied from 0.18 to 0.51 for cognitive tests; the highest effect sizes were ANAM percent accurate $=0.44$, accuracy/time $=0.51$, CPT number omission $=0.35$, CPT reaction time $=0.37$, visual-spatial memory delayed minus immediate recall $=$ 0.33. In the subjects tested before the smoke ban, Cohen's $d$ for the active drug sessions were slightly higher but all under 0.5, except for ANAM percent accurate $=0.57$.

\section{DISCUSSION}

The results of the current experiment are consistent with a small effect of cognitive enhancement of nicotine on attention and visual-spatial memory in schizophrenic patients who are chronic cigarette smokers. Drug effects on the measure of difference in performance between delayed $v s$ immediate error in distance in the dot task have been purported to reflect visual-spatial memory (Keefe et $a l, 1995)$. We are unable to definitively determine whether these effects are cognitively or clinically meaningful, although discussion of effects sizes (below) suggests caution. The apparent effect of nicotine nasal spray on verbal memory that we presented in our original report (Smith et al, 2002) was not replicated in the current study. However, this earlier report compared verbal memory performance in nicotine and placebo nasal spray sessions conducted on different days, whereas the current study compared pre- and post-drug performance scores on the same day.

Our results are consistent with some other recent studies of cognitive effects of smoking and nicotine administration in schizophrenic patients. George et al (2002) reported that both schizophrenic and control smokers had impairment in visual-spatial working memory compared to nonsmoking controls, but that schizophrenics who quit smoking had a further significant decrease in visual-spatial memory. In a recent study this group (Sacco et al, 2005) also showed improvements in visual-spatial working memory in schizophrenic smokers, who had been abstinent from smoking overnight, and interference with this effect by a cholinergic antagonist mecamylamine. However, in the George study, the delayed error measure was significantly different, and in our experiment the difference between delayed and immediate error showed the major effect. Depatie et al (2002) showed an effect of an acute $14 \mathrm{mg}$ nicotine patch on increasing hits on the Cornblatt CPT task, in a design which administered nicotine or placebo patches in different sessions, but did not use a pre-post same session design. Levin et al (1996) reported the effect of acute administration of 7 or $14 \mathrm{mg}$ nicotine patch on decreasing hit reaction time in the Conners CPT task in schizophrenic patients treated with varying doses of haloperidol. They also reported an effect of some doses of nicotine patch on reaction time in the ANAM spatial rotation task, but not on the accuracy or throughput performance scores reported in the current study.

However, Harris et al (2004) recently reported a decrease in attention index on the RBANS neuropsychological battery in a small sample of schizophrenic smokers receiving nicotine gum and an improvement in nonsmoking schizophrenics on this index after nicotine gum. However, in this study's design, smokers were abstinent from smoking for only $2 \mathrm{~h}$ rather than for the $10-12 \mathrm{~h}$ abstinence used in the current study and the previous reports by Smith et al (2002) and Depatie et al (2002). It is possible that differences in the degree of nicotine withdrawal period could influence cognitive effects of nicotine spray, gum, or patch. Furthermore, there were other differences in the design of the two experiments. The Harris study utilized nicotine gum rather than patch or spray, utilized the RBANS rather than the CPT task in this study, and did not use a same day pre-post design utilized in this study. One component of the RBANS attention measure is Digit Span. The RANDT verbal memory test contains a digit span component, and we did not show any significant effects or strong trends for nicotine nasal spray on either forward or backward Digit Span in the current study.

The differences in effects in the nicotine session between subjects who were run before $v s$ after the implementation of the hospital wide smoking ban suggest that some of our cognitive effects may have been due to the $12 \mathrm{~h}$ withdrawal effects from smoking in schizophrenic smokers who regularly smoke cigarettes every day. Although we did not quantitatively assess standard nicotine withdrawal effects (a potential weakness of our design), none of our subjects showed clinical signs of nicotine withdrawal at the beginning of the experimental sessions. However, it is also possible that the number or sensitivity of nicotinic receptors decreased during the several months when the last six subjects were not regularly smoking cigarettes every day.

Although the current study used some additional more specific cognitive measures of attention and visual-spatial memory (CPT, dot task) not included in our earlier study (Smith et al, 2002), the magnitude of the cognitive effects we report here still appeared fairly small. This may imply that desensitization of nicotinic receptors may not be of primary importance in these cognitive effects, or that desensitization occurs quickly even after a single nicotine dose. The single dose and immediate testing design may have not been sufficient to limit receptor desensitization. However, another confounding factor, which may have contributed to the relatively small magnitude of effects, may be the lower nicotine plasma levels (mean $9.4 \mathrm{ng} / \mathrm{ml}$ ) in this study compared to those reported in our original study using this dose (eight puffs each administration) of nicotine nasal spray (mean $18 \mathrm{ng} / \mathrm{ml}$ ). In the original study, subjects received three separate administrations of the same dose of nicotine nasal spray on three occasions over $1.5 \mathrm{~h}$ during which they were tested for psychopathology, affect, and cognitive tasks, and the nicotine levels were measured 30$45 \mathrm{~min}$ after the second nasal spray administration. In the current experiment, they received only a single occasion of nasal spray administration (eight puffs - four puffs each nostril) and completed all cognitive tasks in less than $30 \mathrm{~min}$ after drug administration and had the nicotine sample drawn at this time. Plasma nicotine levels peak about $10 \mathrm{~min}$ after nicotine nasal spray administration with a subsequent elimination half-life of several hours. Pharmacokinetics of multidose administration are similar to single dose, but cumulative blood levels at peak and during elimination halflife are considerably higher (Pharmacia, 1993). Therefore, it is possible that the two separated dosing before nicotine 
blood sample was drawn in the first experiment accounted for the higher nicotine level we reported in the earlier study. However, because we wanted to try to avoid desensitization effects, which may be more prominent with multiple doses, we used a single dose administration design in the current study. However, it is possible that the single dose design did not substantially reduce desensitization. It was not feasible to give more than eight puffs of nicotine nasal spray at one dosing because of the discomfort and side effects from such a high dose of active nasal spray administered at once.

The clinical significance of the cognitive changes, and the specificity of these effects for schizophrenics who have been chronic cigarettes smokers that we report here with nicotine nasal spray is not clear. The effect sizes were quite small and this mitigates against very substantial clinical significance. Cohen suggested that $d$ 's of 0.8 were generally meaningful, and Green and co-workers suggest that Cohen's $d>0.5$ may be clinically significant. Only one Cohen's $d$, on the ANAM task, exceeded this level. We are pursuing additional studies in nonsmoking schizophrenics and nonschizophrenic smokers to investigate the specificity of these effects in schizophrenic smokers. Furthermore, although deficits in attention and visual-spatial memory are established cognitive deficits in schizophrenia, whether the modest neuropsychological test score improvements produced by nicotine on these functions would have meaningful clinical consequences in affecting schizophrenic's cognitive functioning needs to be assessed in clinically meaningful mediating tasks. It would also be important to investigate whether other nicotinic agonists, such as selective $\alpha-7$ derivatives, which do not have as strong effects on desensitization (Stevens et al, 1998), would have stronger effects on cognitive function in schizophrenic patients.

\section{ACKNOWLEDGEMENTS}

This work was supported by a NARSAD Independent Investigator Grant to Dr Smith. Pharmacia-UpJohn provided active and placebo nicotine nasal spray. The authors report no financial conflict of interest in reference to the work reported in this paper. Ms Audrey Meister of the analytical Psychopharmacology Laboratory of Nathan Kline Institute for Psychiatric Research (Director, Tom Cooper) performed the nicotine and cotinine assays.

\section{REFERENCES}

Adler LE, Hoffer LD, Wiser A, Freedman R (1993). Normalization of auditory physiology by cigarette smoking in schizophrenic patients. Am J Psychiatry 150: 1856-1861.

Adler LE, Hoffer LJ, Griffith J, Waldo MC, Freedman R (1992). Normalization by nicotine of deficient auditory sensory gating in the relatives of schizophrenics. Biol Psychiatry 32: 607-616.

Cohen J (1988). Statistical Power Analysis For The Behavioral Sciences, 2nd edn. Lawrence Earlbaum Associates: Hillsdale, NJ.
Dalack GW, Healy DJ, Meador-Woodruff JH (1998). Nicotine dependence in schizophrenia: clinical phenomena and laboratory findings. Am J Psychiatry 155: 1490-1501.

Davis RA (1986). The determination of nicotine and cotinine in plasma. J Chromatogr Sci 24: 134-141.

Depatie L, O'driscoll G, Holahan A-L, Atkinson V, Thavundayuil J, Kin $\mathrm{N}$ et al (2002). Nicotine and behavioral markers of risk for schizophrenia: a double-blind placebo-controlled, cross-over study. Neuropsychopharmacology 27: 1056-1070.

Domino EF (1998). Tobacco smoking and nicotine neuropsychopharmacology: some future research directions. Neuropsychopharmacology 18: 456-468.

George T, Vessicchio J, Termine A, Sahady D, Hear C, Pepper T et al (2002). Effects of smoking abstinence on visuospatial working memory function in schizophrenia. Neuropharmacology 26: 75-85.

Glassman A (1993). Cigarette smoking: implications for psychiatric illness. Am J Psychiatry 150: 546-553.

Harris J, Kongs S, Allenworth D, Martin L, Tregellas J, Sullivan B et al (2004). Effects of nicotine on cognitive deficits in schizophrenia. Neuropsychopharmacology 29: 1378-1385.

Keefe R, Roitman S, Harvey P, Blum C, DuPre R, Prieto D et al (1995). A pen-and-paper human analogue of a monkey prefrontal cortex activation task: spatial working memory in patients with schizophrenia. Schizophr Res 17: 25-33.

Levin ED, Wilson W, Rose JE, McEvoy J (1996). Nicotinehaloperidol interactions and cognitive performance in schizophrenics. Neuropsychopharmacology 15: 429-436.

Olincy A, Ross RG, Young DA, Roath M, Freedman R (1998). Improvement in smooth pursuit eye movements after cigarettes smoking in schizophrenics. Neuropsychopharmacology 18: 175-185.

Pharmacia K (1993). Nicorette: Nicotine Nasal Spray Monograph. Adis International Limited: Chester, England.

Psychological Corporation (1988). Connors Continuous Performance Test. Harcourt Brace and Company: San Antonio.

Randt CT, Brown ER (1983). Administration Manual: Randt Memory Test. Life Science Associates: Bayport, New York.

Reeves D, Kane R, Winter K, Raynsfor K, Pancella R (1993). Automated Neuropsycholgical Assessment Metrics (ANAM): Test Administration Guide, Version 1.0. Institute of Mental Health: St Louis, Missouri.

Russel M, Jarvis M, Feyerbbend C (1983). Nasal nicotine solution: a potential aid to giving up smoking. $\mathrm{Br}$ Med J 286: 683-683.

Sacco KA, Termine A, Seyal A, Dudas MM, Vessicchio JC, Krishnan-Sarin S et al (2005). Effects of cigarette smoking on spatial working memory and attentional deficits in schizophrenia: involvement of nicotinic receptor mechanisms. Arch Gen Psychiatry 62: 649-659.

Smith R, Infante M, Singh A, Khandat A (2001). Olanzapine's effects on neurocognitive functioning in medication refractory schizophrenia. Int J Neuropsychopharmacol 4: 239-250.

Smith RC, Singh A, Infante M, Khandat A, Kloos A (2002). Effects of smoking and nicotine nasal spray on psychiatric symptoms and cognition in schizophrenia. Neuropsychoharmacology 27: 479-497.

Stevens K, Kem W, Mahnor V, Freedman R (1998). Selective alpha7 nicotinic agonist normalize inhibition of auditory response in DBA mice. Psychopharmacology 136: 320-327. 